\title{
ORIGINAL ARTICLE \\ Does population size affect genetic diversity? A test with sympatric lizard species
}

\author{
MTJ Hague ${ }^{1,2}$ and EJ Routman ${ }^{1}$
}

Genetic diversity is a fundamental requirement for evolution and adaptation. Nonetheless, the forces that maintain patterns of genetic variation in wild populations are not completely understood. Neutral theory posits that genetic diversity will increase with a larger effective population size and the decreasing effects of drift. However, the lack of compelling evidence for a relationship between genetic diversity and population size in comparative studies has generated some skepticism over the degree that neutral sequence evolution drives overall patterns of diversity. The goal of this study was to measure genetic diversity among sympatric populations of related lizard species that differ in population size and other ecological factors. By sampling related species from a single geographic location, we aimed to reduce nuisance variance in genetic diversity owing to species differences, for example, in mutation rates or historical biogeography. We compared populations of zebra-tailed lizards and western banded geckos, which are abundant and short-lived, to chuckwallas and desert iguanas, which are less common and long-lived. We assessed population genetic diversity at three protein-coding loci for each species. Our results were consistent with the predictions of neutral theory, as the abundant species almost always had higher levels of haplotype diversity than the less common species. Higher population genetic diversity in the abundant species is likely due to a combination of demographic factors, including larger local population sizes (and presumably effective population sizes), faster generation times and high rates of gene flow with other populations.

Heredity (2016) 116, 92-98; doi:10.1038/hdy.2015.76; published online 26 August 2015

\section{INTRODUCTION}

Genetic diversity is the basic currency of evolution: only genetically variable loci are capable of evolutionary change. However, much work remains to be done to understand the factors responsible for generating and maintaining genetic variation in populations (Leffler et al., 2012). Under a neutral model, a population's genetic diversity depends on its effective population size and the gene's mutation rate (Kimura, 1983). Most evolutionary studies default to a neutral expectation as the null model (Kreitman, 1996; Fay and $\mathrm{Wu}, 2003$ ). However, the apparent lack of a relationship between genetic diversity and population size in wild populations has led some authors to argue that population size and genetic drift are not major factors affecting molecular variation (Lewontin, 1974; Nachman, 1997; Amos and Harwood, 1998; Gillespie, 2001; Bazin et al., 2006).

Central to this criticism is the observation that the range of genetic diversity values from comparisons among taxa with different population sizes is too low to be explained solely by neutral phenomena (Lewontin, 1974). However, many of the comparisons used to bolster this contention are among taxonomically very divergent species, for example, humans vs Drosophila sp. vs bacteria or mammals vs mollusks (Lewontin, 1974; Bustamante et al., 2005; Bazin et al., 2006). Although these taxa do differ in population size, they also potentially differ in many other factors that could affect genetic diversity, for example, geographic location, population history, mutation rates and/or population subdivision, making it difficult to determine the effect of population size.

More recently, a handful of studies have increased the taxonomic breadth of sampling efforts. Although most of these studies did not find a convincing relationship between genetic diversity and population size (Nabholz et al., 2008; Leffler et al., 2012; Perry et al., 2012), one did find a significant relationship between diversity and lifehistory traits that are potentially correlated with population size, such as body mass or propagule size (Romiguier et al., 2014). However, diversity estimates were derived from collections of individuals sampled across large geographic regions, for example, Europe, Canada and Brazil. The conflation of within- and among-population genetic diversity and the lack of control for different climatic, historical and geological phenomena make drawing conclusions about the ultimate causes of genetic diversity difficult.

In contrast to previous studies, determining which evolutionary mechanisms are actually responsible for genetic diversity is facilitated by comparing more closely related species that differ in significant aspects of life history or ecology (Leffler et al., 2012; Cutter and Payseur, 2013), especially if the species are sympatric. Closely related species are more likely to have similar mutation/substitution rates compared with distantly related species (Martin and Palumbi, 1993; Lynch 2010), and sympatric species are more likely to have been exposed to the same climatic and geological histories than are allopatric species. The reptile community at the Mojave National 
Preserve (MNP) in San Bernardino County, CA, USA is an excellent model system for the investigation of genetic diversity because of the large number of sympatric species with different population sizes and demographic properties. The goal of this study is to characterize population levels of molecular genetic diversity in single populations of four lizard species sampled over the same small geographic region. Two of these species have larger population sizes than the other two species.

Our laboratory recently conducted a population study of light/dark color polymorphism in a population of side-blotched lizards (Uta stansburiana) at the Cima Volcanic Field in the MNP. We examined the cytochrome $b$ (cytb) and $\mathrm{NADH}$ dehydrogenase 4 (ND4) mitochondrial loci and the autosomal melanocortin 1 receptor $(M C 1 R)$ locus (Micheletti et al., 2012). Population studies have shown $M C 1 R$ to affect melanin production in other species and the mitochondrial genes were used as potentially non-selected markers. Although the analysis did not find an association among $M C 1 R$ haplotypes and color morphs, we did discover an extraordinary amount of genetic diversity in the population of $U$. stansburiana. Mitochondrial haplotype diversity $(h)$ in the $U$. stansburiana sampled across $12 \mathrm{~km}$ of the lava field was 0.985 , similar to diversity values found in globally sampled marine fish, for example, wahoo and squirrelfish (Micheletti et al., 2012). MC1R was also unexpectedly variable in $U$. stansburiana, especially for an autosomal protein-coding region. Micheletti et al. (2012) found 54 unique haplotypes and a haplotype diversity of 0.919 ( $N=220$ genes). Because $U$. stansburiana is sympatric with a large number of other squamate reptile species that vary in abundance, comparison of genetic diversity among these lizards and snakes provides a test of the effect of population size on diversity without the confounding effects created by sampling from different localities.

In this study, we sampled four additional lizard species sympatric with $U$. stansburiana at the MNP to document how levels of population genetic diversity vary among different species, two species with large population sizes and two species with smaller population sizes. We seek to relate population size to variation in levels of genetic diversity in order to test the predictions of neutral theory. If population size contributes to the maintenance of genetic diversity, we expect the high-density species to have significantly higher levels of diversity. Alternatively, if population size is not an important determinant of diversity, we expect diversity to vary among species or loci irrespective of each species' population size.

\section{MATERIALS AND METHODS}

\section{Sampling and choice of species}

We sampled four species: zebra-tailed lizards (Callisaurus draconoides), western banded geckos (Coleonyx variegatus), chuckwallas (Sauruomalus ater), and desert iguanas (Dipsosaurus dorsalis). Similar to U. stansburiana, C. draconoides and C. variegatus are small-bodied, insectivorous and very abundant at the MNP (Persons and Nowak, 2007). In contrast, S. ater and D. dorsalis are largebodied species, primarily herbivorous and less numerous (Persons and Nowak, 2007). In addition, our study site is centrally located within the ranges of all of the species (Jones and Lovich, 2009), so that diversity reduction associated with edge of range effects or marginal habitat is unlikely to be an issue. Moreover, sampling the four species from the same location in MNP increases the likelihood that all the populations have experienced a roughly coincident biogeographic history. With two similar species in each experimental group, our population survey at the MNP is a replicated analysis of variation in the levels of molecular diversity.

We are confident of the designations of these species as high- vs low-density populations. The results of the only survey of the herpetofauna (Persons and Nowak, 2007) are consistent with our classification, as is our own experience catching these lizards at the MNP over the past 19 years. Three of these four species, in addition to $U$. stansburiana, are diurnal lizards that spend most of their activity time basking on rocks, with occasional forays to forage. A typical search for lizards involves walking a transect while scanning rocks and ground for basking lizards. During these searches, we typically encounter 15-20 $U$. stansburiana and $C$. draconoides for every individual of $D$. dorsalis or $S$. ater, even in optimal habitat for the less common species. The nocturnal C. variegatus are sampled by driving the main paved road through the MNP and sampling the lizards as they cross the roads. C. variegatus is the most common reptile species seen on the road by far, and in normal years a sample of 40 lizards would be easily collected over several nights. Unfortunately, our study was conducted during a drought year, which seemed to depress C. variegatus activity, as well as that of other species.

We haphazardly collected individuals from the MNP in the region of the Cima Volcanic Field (Figure 1, data available from the Dryad Digital Repository: http://dx.doi.org/10.5061/dryad. g7d1r). Samples consisted of 35 S. ater, 21 D. dorsalis, 35 C. draconoides and 21 C. variegatus. Diurnal lizards were captured using a slip-knot noose. Nocturnal C. variegatus were captured by hand. A $0.2-\mathrm{cm}$ tail-tip tissue sample was taken from all individuals and preserved in $95 \%$ ethanol for genetic analysis.

Considering the limited geographic distribution of our samples, we are confident that these samples are from a single population for each species. The largest geographic distances between any two individuals in our sample were found in C. draconoides $(12 \mathrm{~km})$ and C. variegatus $(18 \mathrm{~km})$, but most samples were collected over a much more localized area and suitable habitat was continuous between individuals. A few of the samples for C. draconoides (4 lizards) and C. variegatus (3 lizards) were somewhat geographically separate from the majority of the individuals collected, but reanalysis of the data excluding these individuals had no effect on any of the genetic parameter estimates described below.

\section{Locus choice and molecular methods}

For consistency with the $U$. stansburiana study, we surveyed the $c y t b$ and $M C 1 R$ genes in all four species. For a better depiction of the standing level of genetic
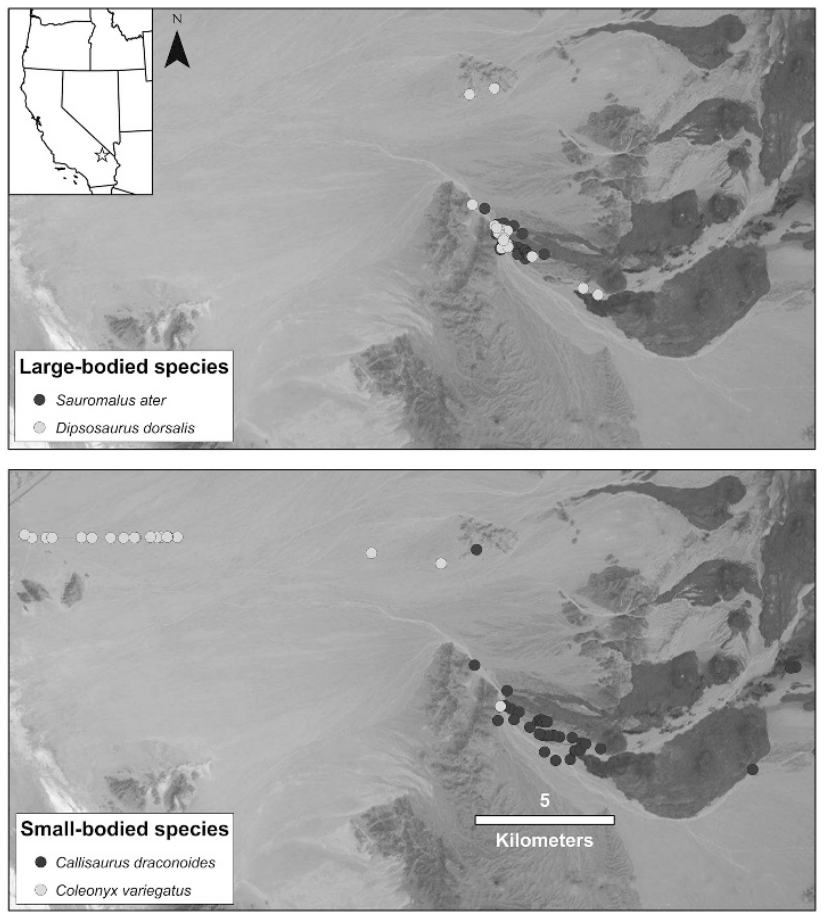

Figure 1 Satellite imagery of the Cima Volcanic Field region of the Mojave National Preserve with collecting localities. Star on map inset indicates location of the maps. 
Table 1 Molecular diversity summary statistics

\begin{tabular}{|c|c|c|c|c|c|c|c|c|c|}
\hline Species & $b p$ & $\mathrm{~N}$ & Variable sites & Syn. sub. & Nonsyn. sub. & Number of haplotypes & $\mathrm{h}$ & $\pi$ & $\theta$ \\
\hline \multicolumn{10}{|l|}{ cytb } \\
\hline S. ater & 855 & 35 & 12 & 8 & 4 & 5 & $0.5899( \pm 0.0958)$ & $0.0034( \pm 0.0040)$ & $0.0034( \pm 0.0027)$ \\
\hline C. draconoides & 1027 & 35 & 31 & 28 & 3 & 19 & $0.9613( \pm 0.0282)$ & $0.0063( \pm 0.0067)$ & $0.0073( \pm 0.0049)$ \\
\hline C. variegatus & 845 & 21 & 34 & 25 & 9 & 14 & $0.9476( \pm 0.0615)$ & $0.0140( \pm 0.0145)$ & $0.0112( \pm 0.0081)$ \\
\hline D. dorsalis & 757 & 42 & 3 & 3 & 0 & 4 & $0.5250( \pm 0.1329)$ & $0.0008( \pm 0.0015)$ & $0.0009( \pm 0.0011)$ \\
\hline C. draconoides & 815 & 70 & 30 & 29 & 1 & 38 & $0.9743( \pm 0.0141)$ & $0.0061( \pm 0.0065)$ & $0.0076( \pm 0.0047)$ \\
\hline C. variegatus & 665 & 42 & 13 & 12 & 1 & 14 & $0.9001( \pm 0.0419)$ & $0.0037( \pm 0.0045)$ & $0.0045( \pm 0.0035)$ \\
\hline \multicolumn{10}{|l|}{ RAG1 } \\
\hline S. ater & 1055 & 70 & 9 & 6 & 3 & 8 & $0.7366( \pm 0.0625)$ & $0.0018( \pm 0.0023)$ & $0.0018( \pm 0.0014)$ \\
\hline
\end{tabular}

Abbreviations: cytb, cytochrome $b$; MC1R, melanocortin 1 receptor; RAG1, recombination activation gene-1. Summary statistics for the mitochondrial locus cytb and the autosomal loci $M C 1 R$ and $R A G 1$. Included is the number of base pairs sequenced (bp), number of genes sampled $(N)$, number of variable sites, number of positions with synonymous (Syn. sub.) and nonsynonymous (Nonsyn. sub.) base changes, number of haplotypes and haplotype diversity $(h)$, Nei's $\theta(\pi)$, and Watterson's $\theta(\theta)$ with $95 \%$ confidence intervals. Reanalysis of the data using only nucleotides positions shared by all four species resulted in almost undetectable changes in summary statistics and are not reported.

diversity, we analyzed an additional autosomal gene: recombination activation gene-1 (RAG1). RAG1 has been successfully used as a marker in higher-level phylogenetic studies, including determining basal divergences in squamate reptiles (Townsend et al., 2004), and therefore is not expected to be highly variable at the within-population level.

Whole genomic DNA was extracted from frozen tissue using the QuickgDNA MiniPrep Kit (Zymo Research, Irvine, CA, USA). Primers for the cytb mitochondrial locus and the MC1R and RAG1 autosomal loci were obtained from previously published studies and developed by aligning sequences from closely related species accessed through GenBank (Supplementary information 1). The target loci were amplified with $20 \mu \mathrm{l}$ PCR reactions (Supplementary information 1) using AccuPower PyroHotStart Taq PCR PreMix (Bioneer, Alameda, CA, USA). Each PCR reaction included $18 \mu \mathrm{l}$ PCR water, $0.5 \mu \mathrm{l}$ of each primer and $1 \mu \mathrm{l}$ of the genomic DNA. The PCR product was cleaned using ExoSAP-IT (Affymetrix, Santa Clara, CA, USA), and the purified product was sequenced in both directions by Elim Biopharmaceuticals, Hayward, CA, USA. Sequences were aligned and edited in Geneious 4.8.5 (Biomatters, available from http://www.geneious.com/). To avoid mistaking poor sequence data for high genetic diversity, sequence chromatograms with indistinct peaks or suspicious base changes were resequenced. Heterozygous sites in the autosomal loci were identified by visual inspection and confirmed in both directions of sequencing.

Haplotype linkage phase was inferred computationally with the program PHASE (Stephens et al., 2001). PHASE can sometimes have difficulty resolving low frequency alleles, and omitting such alleles from analyses can lead to artifactual reductions in estimates of molecular diversity in population studies (Garrick et al., 2010). Individuals with alleles that PHASE could not reliably infer at the $90 \%$ confidence threshold were resolved by cloning and sequencing the PCR product from that locus. The PCR product of heterozygous individuals was cloned using a TOPO TA Cloning Kit for Sequencing (Life Technologies, Grand Island, NY, USA). Multiple clones were sequenced with the same methods used for sequencing of PCR products from genomic templates in order to determine the true haplotypes for each individual.

\section{Intraspecific genetic diversity}

Population genetic analyses were performed with Arlequin 3.5 (Excoffier and Lischer, 2010). Each species was treated as a single population. For each species, we tested for recent population expansion using a pairwise mismatch distribution (Rogers and Harpending, 1992). We tested for significance using the raggedness index ( $r$; Harpending, 1994) and the sum of squared deviation test (Rogers and Harpending, 1992). We also tested for departures from neutral expectations using Tajima's $D$ ( $D$; Tajima, 1989).

To assess molecular diversity, we estimated the number of haplotypes and haplotype diversity $(h)$ at each locus (Nei, 1987). We also estimated nucleotide diversity with Watterson's $\theta$ ( $\theta$; Watterson, 1975) and Nei's $\theta(\pi$; Watterson, 1975; Tajima, 1983). For each locus, we made pairwise comparisons of haplotype diversity between species. Differences in haplotype diversity between species were deemed significant if the $95 \%$ confidence intervals of the two estimates did not overlap by more than half of a one-sided error bar (Cumming and Finch, 2005). We also compared haplotype diversities using a $z$-score test suggested by Nei (1987). To better visualize the genetic diversity at each locus, we constructed haplotype networks for each locus using TCS 1.21 (Clement et al., 2000). Closed loops in the haplotype network were resolved by comparison to a maximum likelihood tree estimated in PAUP* 4.0 (Swofford, 2003).

\section{RESULTS}

The results of our tests for population expansion and deviation from neutral model expectations, along with diversity measures, are summarized in Tables 1-3 and graphically illustrated in Figures 2 and 3. Differences among species in the number of bases sequenced had little-to-no effect on results, based on comparisons with analyses conducted on data sets confined to only shared nucleotide positions (data not shown).

\section{The mitochondrial locus-cytb}

The high-density species $C$. draconoides and $C$. variegatus show higher levels of genetic diversity for cytb than do the low-density species $S$. ater and $D$. dorsalis. This is true for all measures of diversity. The number of variable sites is 2.5-9.5 times greater in the highdensity species (Table 1), resulting in much more complex unrooted haplotype networks (Figure 2). Nei's and Watterson's estimates of $\theta$ are also much higher, although not significantly so because of the large 95\% confidence intervals. Haplotype diversity is significantly higher for the high-density species (Table 1, Figure 3) and similar to the previously published value for $U$. stansburiana, the other abundant lizard species (Micheletti et al., 2012). 
Table 2 Mismatch and neutrality tests

\begin{tabular}{lcccc}
\hline Species & $\mathrm{D}$ & $\mathrm{P}$ & $\mathrm{r}$ & $\mathrm{P}$ \\
\hline cytb & & & & \\
$\quad$ S. ater & 0.004 & 0.54 & 0.515 & 0.01 \\
$\begin{array}{l}\text { D. dorsalis } \\
\text { C. draconoides }\end{array}$ & 0.959 & 0.89 & 0.204 & 0.14 \\
C. variegatus & -0.482 & 0.37 & 0.034 & 0.40 \\
& 0.999 & 0.87 & 0.013 & 0.95 \\
MC1R & & & & \\
S. ater & & & & \\
D. dorsalis & -0.975 & 0.20 & 0.169 & $<0.01$ \\
C. draconoides & -0.180 & 0.44 & 0.109 & 0.35 \\
C. variegatus & -0.646 & 0.30 & 0.020 & 0.16 \\
& -0.555 & 0.33 & 0.030 & 0.66 \\
RAG1 & & & & \\
S. ater & & & & \\
D. dorsalis & 0.071 & 0.60 & 0.094 & 0.39 \\
C. draconoides & -0.084 & 0.51 & 0.054 & 0.13 \\
C. variegatus & -0.614 & 0.31 & 0.032 & 0.41 \\
\hline
\end{tabular}

Abbreviations: cytb, cytochrome $b$; MC1R, melanocortin 1 receptor; RAG1, recombination activation gene-1. Tajima's $D(D)$ and raggedness index $(r)$ for each locus. Significant $P$-values are indicated in bold.

Table 3 Pairwise difference in haplotype diversity $(h)$ among species and maximum within-species sequence divergence

\begin{tabular}{|c|c|c|c|c|}
\hline Species & S. ater & D. dorsalis & C. draconoides & C. variegatus \\
\hline \multicolumn{5}{|l|}{ cytb } \\
\hline S. ater & 1.05 & & & \\
\hline D. dorsalis & 0.1613 & 0.12 & & \\
\hline C. draconoides & 0.3714 & 0.5327 & 1.27 & \\
\hline C. variegatus & 0.3577 & 0.5190 & 0.0137 & 3.08 \\
\hline \multicolumn{5}{|l|}{ MC1R } \\
\hline S. ater & 0.60 & & & \\
\hline D. dorsalis & 0.1276 & 0.40 & & \\
\hline C. draconoides & 0.3217 & 1.4993 & 1.60 & \\
\hline C. variegatus & 0.2475 & 0.3751 & 0.0742 & 0.90 \\
\hline \multicolumn{5}{|l|}{ RAG1 } \\
\hline S. ater & 0.66 & & & \\
\hline D. dorsalis & 0.0421 & 0.66 & & \\
\hline C. draconoides & 0.0800 & 0.1221 & 1.09 & \\
\hline C. variegatus & 0.1716 & 0.2137 & 0.0916 & 1.76 \\
\hline
\end{tabular}

Abbreviations: cytb, cytochrome $b$; MC1R, melanocortin 1 receptor; RAG1, recombination activation gene-1. Pairwise differences in haplotype diversities between species for cytb, MC1R and RAG1. Significant differences are indicated in bold. Italicized values on the diagonal indicate the maximum within-species percentage of sequence divergence (uncorrected) between any two haplotypes.

We have no evidence that selection is operating on $c y t b$. The ratio of synonymous to nonsynonymous base changes is much higher in all species except $D$. dorsalis, which has only one variable base (Table 1). Tajima's $D$ values are not significantly different from 0 for any of the species (Table 2). Pairwise mismatch statistics suggest that only S. ater has a stable population $(P=0.01)$ and that $D$. dorsalis, $C$. draconoides and $C$. variegatus are all undergoing population expansion (Table 2). The sum of squared deviation test gave the same results as the raggedness statistic for all loci and is therefore not shown. The lack of significant Tajima's $D$ values is not consistent with population expansion. Because the raggedness statistic tests the null hypothesis of population expansion, the inability to reject that hypothesis may reflect a lack of power rather than a true population expansion.

\section{The autosomal loci-MC1R and RAG1}

The high-density species show higher levels of autosomal genetic diversity than do the low-density species for all metrics. Molecular diversity at the MC1R locus was surprisingly high for the two highdensity lizard species and for U. stansburiana (Micheletti et al., 2012), given that autosomal protein-coding loci are normally less variable than mitochondrial loci. In fact, $M C 1 R$ haplotype diversity estimates were greater than the mitochondrial cytb values for three of the species, S. ater, D. dorsalis and C. draconoides, although these differences were not statistically significant. As was the case for $c y t b$, C. variegatus and $C$. draconoides MC1R haplotype diversities were significantly larger than those of both $S$. ater and $D$. dorsalis.

We have no evidence that selection is operating on MC1R. The ratio of synonymous to nonsynonymous base changes is much higher in all species (Table 1). As was the case with $c y t b$, Tajima's $D$ values are not significantly different from 0 for any of the species (Table 2) and only $S$. ater has a significant raggedness statistic for the pairwise mismatch distribution (Table 2).

In lizard studies, RAG1 is typically used for phylogenetic analyses, including studies of the deeper taxonomic relationships among squamate reptiles (for example, Townsend et al., 2004). Yet we found relatively high levels of within-population genetic variation at this locus. Levels of genetic diversity for RAG1 are similar to those of the two other genes but with a few important differences. As with the other two genes, the high-density species have more variable sites and higher point estimates of $\theta$ and haplotype diversity (Table 1). However, the low-density species have higher haplotype diversities at RAG1 compared with the other genes, while $C$. draconoides has a somewhat lower value $(h=0.817)$. As a result, only $C$. variegatus has a haplotype diversity value that is significantly higher than that of the other species (Figure 3). Application of the $z$-score test does show that haplotype diversity of $C$. draconoides is significantly greater than $D$. dorsalis $(P=0.04)$ using a significance threshold of $P=0.05$, but the test agrees with the method of Cumming and Finch (2005) if the threshold is Bonferroni corrected for the 18 pairwise comparisons among our species (threshold $P=0.028$ ).

For RAG1, Tajima's $D$ and the value of the raggedness index of the pairwise mismatch distribution are not significantly different from 0 for any species. Unlike the other loci, the number of nonsynonymous base changes exceeds the number of synonymous base changes for three of the species, D. dorsalis, C. draconoides and C. variegatus. For these species, nonsynonymous-to-synonmous ratios of polymorphisms range from 1.4 to 3.5. This may suggest the operation of balancing selection; however, Tajima's $D$ was not significantly different from neutral expectations for any species. In most instances, the two amino acids associated with a nonsynonymous mutation shared similar physical, chemical or structural properties, based on the criteria in Taylor (1986). For example, D. dorsalis and C. draconoides had a limited number of nucleotide positions (three and one, respectively) with mutations that resulted in a switch between two amino acids with different, unique properties. C. variegatus was higher, with five nonsynonymous base changes associated with a switch between dissimilar amino acids. The question remains of whether the RAG1 amino-acid changes are neutral or adaptive.

\section{DISCUSSION}

In general, the differences in genetic diversity we observed among species were consistent with the predictions of neutral theory for both 


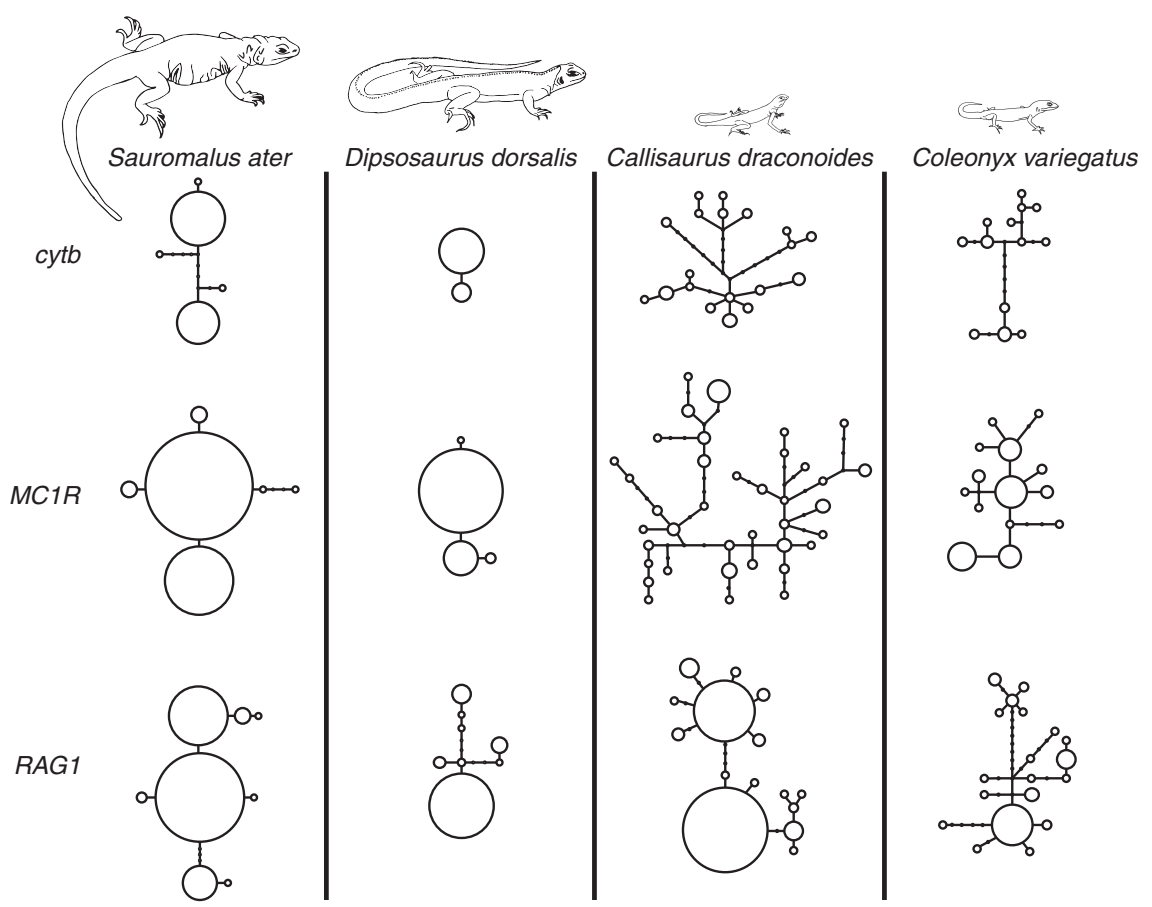

Figure 2 Haplotype networks of the cytb, MC1R and RAG1 genes for four species of lizards from the Mojave National Preserve. Circle size is proportional to the number of samples of a given haplotype. Lines between haplotypes represent mutational steps between haplotypes. The solid dots on the lines represent unobserved, inferred haplotypes.

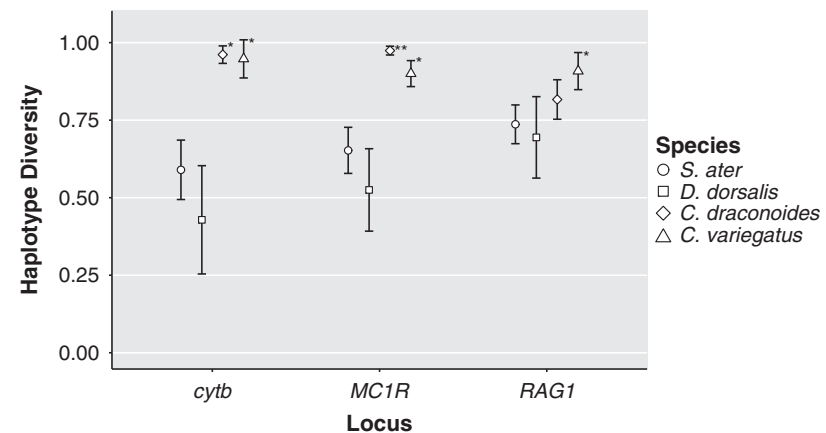

Figure 3 Haplotype diversities ( $h$ ) for the cytb, MC1R and RAG1 genes for four species of lizards from the Mojave National Preserve. Error bars represent 95\% confidence intervals around the point estimates of $h$. *Indicates statistically significantly higher diversities for comparisons between high- and low-density species based on confidence interval overlap (Cumming and Finch, 2005). An additional asterisk indicates statistically significantly higher diversities within high-density species.

mitochondrial and autosomal loci. Patterns of polymorphism were largely consistent with a neutral model of sequence evolution, and the high-density species had significantly higher levels of genetic diversity than the less common ones. These results illustrate that sympatric species can differ, sometimes dramatically, in diversity. The high haplotype diversities observed in $C$. draconoides and C. variegatus compared with those of $S$. ater and $D$. dorsalis could be due to several factors. Foremost, the large populations of $C$. draconoides and C. variegatus at the MNP are likely an important contributing factor to the high molecular diversity. Calisaurus draconoides was one of the most frequently encountered lizard species in a survey of reptiles and amphibians on the MNP (Persons and Nowak, 2007). Espinoza (2009) states that $C$. variegatus '...is among the most frequently encountered desert reptiles in the Southwest'. From our field experience at the collecting site, covering more than 19 years, we are confident that C. draconoides and C. variegatus are both very abundant in the MNP, especially given the widespread distribution of favorable habitat for both species. These two small-bodied species also have many demographic similarities to $U$. stansburiana, the aforementioned species with high levels of genetic diversity at the same location in the MNP. $U$. stansburiana is by far the most abundant lizard in the MNP (Persons and Nowak, 2007).

Conversely, S. ater and D. dorsalis are undoubtedly less abundant at the preserve. Despite being large and easily observed, both species had low encounter rates in the MNP inventory (Persons and Nowak, 2007). At the MNP, S. ater are found exclusively in rocky areas with large boulders, a habitat which occupies a much smaller geographic area than habitat favored by $C$. draconoides, $C$. variegatus and $U$. stansburiana. Despite the prominence of suitable habitat for $D$. dorsalis at the site, our observations suggest that the species is much less abundant than the small-bodied lizard species. Daytime encounter rates for $D$. dorsalis are much lower than for U. stansburiana and C. draconoides.

Consequently, the high- and low-density species almost certainly also differ in effective population size at MNP. Under a neutral model, populations with a larger effective population size $\left(N_{\mathrm{e}}\right)$ are expected to have a greater number of neutral mutations (Kimura, 1983). A population's genetic variation at a particular locus is dictated by its effective population size and the gene's mutation rate $(\mu)$. The probability of heterozygosity (that is, haplotype diversity) is

$$
H=\frac{\theta}{\theta+1}
$$


where $\theta=4 N_{\mathrm{e}} \mu$ (autosomal genes) or $\theta=N_{\mathrm{e}} \mu$ (mitochondrial genes). Effective population size is also the critical variable that determines genetic diversity in coalescent models (Charlesworth, 2009). Although we believe the high-density species have larger effective population sizes than the low-density ones, we do not report coalescent effective population size estimates. This study, along with all studies examining the role of population size on genetic diversity, is constrained to use of census population size as a proxy for the coalescent effective population size. Without longterm pedigree data, the only way to estimate coalescent effective population size is through simulations with empirical genetic diversity data, using models that assume an inherent relationship between genetic diversity and population size (that is, the relationship we seek to test). Therefore, we avoid estimates of effective population size for the purposes of this study. However, if the biogeographic histories of the lizard species at MNP are roughly similar, census population size should be roughly proportional to effective population size by a similar degree for all four species. We believe this is a reasonable assumption, given our samples were collected from sympatric populations.

Generation time may be another demographic factor contributing to differences in genetic diversity in the four species. Longer generation times mean there are fewer generations between the present and any past causes of reduced genetic variation, such as founder events or population bottlenecks. If such events occurred at similar times in the past for all species, recovery of genetic polymorphism would take longer in the less abundant species. Both $S$. ater and $D$. dorsalis have greater longevity and longer generation times than the more diverse species. Estimates for $S$. ater longevity range up to 15 years in the wild, and juveniles may take up to 3 years to reach sexual maturity (Sullivan and Sullivan, 2012). D. dorsalis also has a late maturation, with longevity estimates ranging from 7.5 to 14 years (Krekorian, 1984). The high-density species for which we have genetic data (C. draconoides, C. variegatus, U. stansburiana) tend to mature in $<1$ year and have much lower annual survival than the less genetically diverse species (Tanner and Krogh, 1975). The combination of shorter generation times and larger population sizes are probably important demographic contributors to the higher neutral genetic diversity observed in $C$. draconoides, $C$. variegatus and $U$. stansburiana compared with $S$. ater and $D$. dorsalis.

Surrounding populations at MNP may also contribute to increased diversity through gene flow and population mixing. High levels of gene flow can produce high within-population diversity by increasing the effective population size of a local population. Because the habitat suitable for $C$. draconoides, $C$. variegatus and $U$. stansburiana is so widespread in this region of the Mojave Desert, there is potential for gene immigration from tens or even hundreds of kilometers from our sample sites. Alternatively, gene flow may be limited in the less abundant species. For example, S. ater migration is probably restricted at the MNP owing to the long distances between rocky outcrops. For $D$. dorsalis, estimates of home range in the literature range up to 0.20 hectares (Krekorian, 1976). However, similar to the abundant species, $D$. dorsalis has a large amount of suitable habitat at the MNP and surrounding regions. Therefore, limited gene flow by itself cannot explain the lower genetic diversity in both $S$. ater and $D$. dorsalis. The contribution of gene flow from other populations to genetic diversity can only be evaluated by genetic studies of surrounding populations and estimation of gene flow rates.

Other factors unrelated to demography may also be responsible for the differences in genetic diversity among the lizard species. Two of the high-density/high genetic diversity species (C. draconoides and
U. stansburiana) and the two low-density/low genetic diversity species (S. ater and $D$. dorsalis) are all in the Pleurodonta section of the Iguania; however, $U$. stansburiana and $C$. draconoides are in the family Phrynosomatidae and S. ater and D. dorsalis are in the Iguanidae. Thus population size is confounded with phylogeny at the family level. This is somewhat mitigated by the fact that we also found high genetic diversity in C. variegatus, despite this species being in the Gekkota family Eublepharidae, a phylogenetically divergent group in relation to Iguania (Pyron et al., 2013). Ultimately, the effects of phylogeny can only be ruled out if the correlation between population size and diversity is consistent across multiple taxonomic comparisons. At the MNP, we are currently sampling other species in a variety of squamate families, including Phrynosomatidae, Crotaphytidae, Teiidae, Colubridae and Crotalidae, in order to increase taxonomic representation and test whether the relationship between population size and genetic diversity holds across families within the Squamata.

Taken together, our data are consistent with neutral models that predict a relationship between genetic diversity and population size. Alternative evolutionary forces have been proposed as major drivers of differences in population genetic diversity, for example recurrent selection and 'genetic draft' (Smith and Haigh, 1974; Gillespie, 2001; Bazin et al., 2006). Although we cannot rule out the importance of other such forces, our data are predominantly consistent with the predictions of neutral theory. Ultimately, no one study can validate the generality of a relationship between genetic diversity and population size. Our current and future work on MNP reptiles must be replicated from taxonomically independent sets of closely related sympatric species sampled from a variety of different higher taxa. Moving forward, studies should also utilize next-generation sequencing technology in order to survey a large number of genes throughout the genome. This study of reptiles represents a single step in the process of resolving the evolutionary forces that maintain genetic diversity in natural populations.

\section{DATA ARCHIVING}

DNA sequences: Genbank accession numbers: KR026343-KR026902. Lizard sample locality data, with associated Genbank numbers, available from the Dryad Digital repository: http://dx.doi.org/ 10.5061/dryad.g7d1r

\section{CONFLICT OF INTEREST}

The authors declare no conflict of interest.

\section{ACKNOWLEDGEMENTS}

We thank S Parra, C Clarkson Smith and N Graham for help with field collections. We thank the National Park Service for access the Mojave National Preserve. We also thank R Fulton and J Wallace for their hospitality at the CSU Desert Studies Center. J de la Torre was generous in providing his help with cloning. G Spicer and E Connor provided valuable comments and statistical advice. The comments of three anonymous reviewers greatly improved the manuscript. This research was funded by an Office of Research and Sponsored Programs Mini-Grant to EJR and a Biology Arthur Nelson Graduate Scholarship to MTJH, both from San Francisco State University. All procedures involving animals were approved by the SFSU IACUC under protocol A12-02.

Amos W, Harwood J (1998). Factors affecting levels of genetic diversity in natural populations. Philos Trans R Soc Lond B Biol Sci 353: 177-186.

Bazin E, Glémin S, Galtier N (2006). Population size does not influence mitochondrial genetic diversity in animals. Science 312: 570-572. 
Bustamante CD, Fledel-Alon A, Williamson S, Nielsen R, Todd Hubisz M, Glanowski S et al. (2005). Natural selection on protein-coding genes in the human genome. Nature 437 1153-1157.

Charlesworth B (2009). Effective population size and patterns of molecular evolution and variation. Nat Rev Genet 10: 195-205.

Clement M, Posada D, Crandall KA (2000). TCS: a computer program to estimate gene genealogies. Mol Ecol 9: 1657-1659.

Cumming G, Finch S (2005). Inference by eye: confidence intervals and how to read pictures of data. Am Psychol 60: 170-180.

Cutter AD, Payseur BA (2013). Genomic signatures of selection at linked sites: unifying the disparity among species. Nat Rev Genet 14: 262-274.

Espinoza RE (2009). Western banded gecko. In: Jones LC, Lovich RE (eds). Lizards of the American Southwest, Rio Nuevo Publishers: Tucson, AZ, USA, pp 312-315.

Excoffier L, Lischer HEL (2010). Arlequin suite ver 3.5: a new series of programs to perform population genetics analyses under Linux and Windows. Mol Ecol Resour 10: 564-567.

Fay JC, Wu Cl (2003). Sequence divergence, functional constraint, and selection in protein evolution. Annu Rev Genomics Hum Genet 4: 213-235.

Garrick RC, Sunnucks P, Dyer RJ (2010). Nuclear gene phylogeography using PHASE: dealing with unresolved genotypes, lost alleles, and systematic bias in parameter estimation. BMC Evol Biol 10: 118.

Gillespie JH (2001). Is the population size of a species relevant to its evolution? Evolution 55: 2161-2169.

Harpending HC (1994). Signature of ancient population growth in a low-resolution mitochondrial DNA mismatch distribution. Hum Biol 66: 591-600.

Jones L, Lovich R (eds). (2009). Lizards of the American Southwest. Rio Nuevo Publishers: Tucson, AZ, USA.

Kimura M (1983). The Neutral Theory of Molecular Evolution. Cambridge University Press: Cambridge [Cambridgeshire]; New York, NY, USA.

Kreitman M (1996). The neutral theory is dead. Long live the neutral theory. Bioessays 18: 678-683.

Krekorian CO (1976). Home range size and overlap and their relationship to food abundance in the desert iguana, Dipsosaurus dorsalis. Herpetologica 32: 405-412.

Krekorian CO (1984). Life history of the desert iguana, Dipsosaurus dorsalis. Herpetologica 40: 415-424.

Leffler EM, Bullaughey K, Matute DR, Meyer WK, Ségurel L, Venkat A et al. (2012). Revisiting an old riddle: what determines genetic diversity levels within species? PLOS Biol 10: e1001388.

Lewontin RC (1974). The Genetic Basis of Evolutionary Change. Columbia University Press: New York, USA.

Lynch M (2010). Evolution of the mutation rate. Trends Genet 26: 345-352.

Martin AP, Palumbi SR (1993). Body size, metabolic rate, generation time and the molecular clock. Proc Natl Acad Sci USA 90: 4087-4091.
Micheletti S, Parra E, Routman EJ (2012). Adaptive color polymorphism and unusually high local genetic diversity in the side-blotched lizard, Uta stansburiana. PLoS One 7: e47694.

Nabholz B, Mauffrey J-F, Bazin E, Galtier N, Glémin S (2008). Determination of mitochondrial genetic diversity in mammals. Genetics 178: 351-361.

Nachman MW (1997). Patterns of DNA variability at X-Linked loci in Mus domesticus. Genetics 147: 1303-1316.

Nei M (1987). Molecular Evolutionary Genetics. Columbia University Press: New York, NY USA.

Perry GH, Melsted P, Marioni JC, Wang Y, Bainer R, Pickrell JK et al. (2012). Comparative RNA sequencing reveals substantial genetic variation in endangered primates. Genome Res 22: 602-610.

Persons TB, Nowak EM (2007). Inventory of Amphibians and Reptiles at Mojave National Preserve: Final Report. US Geological Survey: Flagstaff, AZ, USA.

Pyron RA, Burbrink FT, Wiens JJ (2013). A phylogeny and revised classification of Squamata, including 4161 species of lizards and snakes. BMC Evol Biol 13: 93.

Rogers AR, Harpending $H$ (1992). Population growth makes waves in the distribution of pairwise genetic differences. Mol Biol Evol 9: 552-569.

Romiguier J, Gayral P, Ballenghien M, Bernard A, Cahais V, Chenuil A et al. (2014). Comparative population genomics in animals uncovers the determinants of genetic diversity. Nature 515: 261-263.

Smith JM, Haigh J (1974). The hitch-hiking effect of a favourable gene. Genet Res 23 . 23-35.

Stephens M, Smith NJ, Donnelly P (2001). A new statistical method for haplotype reconstruction from population data. Am J Hum Genet 68: 978-989.

Sullivan BK, Sullivan KO (2012). Common chuckwalla (Sauromalus ater) in an urban preserve: persistence of a small population and estimation of longevity. Herpetol Conserv Biol 7: 437-441.

Swofford DL (2003). PAUP* Phylogenetic Analysis Using Parsimony (*and Other Methods). Sinauer Associates: Sunderland, Massachusetts, USA.

Tajima F (1983). Evolutionary relationship of DNA sequences in finite populations. Genetics 105: 437-460.

Tajima F (1989). The effect of change in population size on DNA polymorphism. Genetics 123: 597-601.

Tanner WW, Krogh JE (1975). Ecology of the zebra-tailed lizard Callisaurus draconoides at the Nevada Test Site. Herpetologica 31: 302-316.

Taylor WR (1986). The classification of amino acid conservation. J Theor Biol 119: 205-218.

Townsend TM, Larson A, Louis E, Macey JR (2004). Molecular phylogenetics of Squamata: the position of snakes, amphisbaenians, and dibamids, and the root of the squamate tree. Syst Biol 53: 735-757.

Watterson G (1975). On the number of segregating sites in genetical models without recombination. Theor Popul Biol 7: 256-276.

Supplementary Information accompanies this paper on Heredity website (http://www.nature.com/hdy) 